BULGARIAN ACADEMY OF SCIENCES

CYBERNETICS AND INFORMATION TECHNOLOGIES • Volume 15, No 4

Sofia $\bullet 2015$

Print ISSN: 1311-9702; Online ISSN: 1314-4081

DOI: $10.1515 /$ cait-2015-0057

\title{
Bridging the Gap between Digital Libraries and e-Learning
}

\author{
Milena Dobreva ${ }^{1}$, Galia Angelova ${ }^{2}$, Gennady Agre ${ }^{2}$ \\ ${ }^{1}$ Department of Library Information and Archive Sciences, University of Malta \\ ${ }^{2}$ Institute of Information and Communication Technologies, BAS, Sofia, Bulgaria \\ Emails: milena.dobreva@um.edu.mt_galia@lml.bas.bgａgre@iinf.bas.bg
}

Abstract: Digital Libraries (DL) are offering access to a vast amount of digital content, relevant to practically all domains of human knowledge, which makes it suitable to enhance teaching and learning. Based on a systematic literature review, this article provides an overview and a gap analysis of educational use of DLs.

Keywords: e-Learning, digital libraries, personas, scenarios, digitisation priorities.

\section{Introduction}

\subsection{Background}

The amount of digitised content is constantly growing in the last decades. Digitisation which had been initially conceived as a way to achieve twofold impact by improving access to the abundant content stored in memory institutions (libraries, archives, museums and art galleries), and by preserving digital surrogates for content which eventually will disintegrate or may be at risk [1], gradually progressed from a state-of-the-art to a routine activity. Digitised content is currently being organised in digital libraries which serve as gateways to electronic resources.

A particularly popular segment of digital libraries offers access to digitised (and in some cases to born digital) cultural and scientific heritage developed systematically as an outcome of the mass digitisation efforts of memory institutions. Some examples of popular digital libraries from this domain are the World Digital Library which is guided by the principle of exquisiteness and it currently offers access to 12,300 objects [2]; the flagship project of the European Commission Europeana which provides access to over 45 million digital objects [3]; the Digital Public Library of America (DPLA) which brings together over 9 million digitised objects from the cultural heritage domain [4]. Besides these efforts spearheaded by memory institutions, there are industry-driven projects. The most prominent one in the digitisation domain is of Google Books which started in 2002 and reached a 
milestone of 1 million digitised books by 2007 [5], and progressed to an estimate of 30 million by 2013 out of the total assessment of some 130 million published books altogether from the dawn of book printing until now.

What impact and use do these digitised resources have? While the purchases and/or downloads of digital books, for example, are closely monitored by the industrial sector and there is a generic picture of the resulting markets [6], more refined data on specific areas of use such as education remain insufficiently defined. Is the complete lack of mention of digital libraries in e-Learning market trends and forecasts [7] an unfortunate oversight or they do not really have any substantial role to play in the learning sector? How is it possible to consider both digital libraries and eLearning as parts of a national digital content strategy without noting the possible synergies between those two domains, as it is the case in [8]? Furthermore, why digital libraries are not addressed in detail in the extensive recent two-volume "Handbook of Research on Didactic Strategies and Technologies for Education: Incorporating Advancements" [9]? We argue that while digital libraries have the potential to support e-Learning, there is a broken link between the current provision of digital libraries targeting learning due to the fact that most work in this area is based on the ideas of digital library developers how their resources can be used in education, rather than on a sound knowledge of the needs of the educators and learners; this paper looks at possible ways to bridge the existing gap.

The great promise for educational relevance of digital libraries is due to the nature of resources they bring together. These resources can be used to illustrate a variety of educational topics in practically all areas of knowledge, or to support individual learning. Indeed, the potential usefulness in teaching is a constantly recurring theme within the scientific body of knowledge which explores the potential impact and the real use of digital collections. While earlier views on increasing impact of digital libraries looked at discoverability aspects and tools like search engine optimisation and RSS feeds [10], a steady interest to the contexts of use of digital collections was developed in the last years. For example Tanner and Deegan delineate the use areas for digital content, with learning, teaching, research, and enjoyment being of largest prominence [11]. They summarise the benefits for use of digital libraries in teaching, as follows: "The increasing availability of digitised resources allows educational institutions to provide students with more varied, more accessible and richer teaching materials than ever before. This encourages a more exploratory, research based approach to teaching and learning. Entirely new kinds of topics and courses can be studied, new modes of assessment are possible, and students are given a richer educational experience." [11] Such a view is echoed by an earlier study coming from a different area of knowledge, geography: "Digital libraries hold great potential for educational applications, as they can provide access to a wide array of information resources that are essential for inquiry" [12]. Indeed, the use of digital libraries material in teaching looks like a most natural area of use. In the case of cultural heritage libraries, their rich materials could be used to illustrate lessons in history, social history, languages, literature, music, and art. However, in reality the use of digital libraries in teaching still remains limited and the most popular evidence requires the contribution of 
particularly enthusiastic teachers, as summarised in $[13$, p. 6] a decade ago - with no sufficient evidence that the situation changed considerably over the last years. "Despite teachers' self-reports on the value of learning resources, the NSDL, the IA and their positive impacts on education, persistent use remains difficult to obtain. Only a small portion of workshop attendees and organic users created multiple and complex projects. We note that this is not an uncommon finding in the teacher professional development literature, whereby attendees report positive experiences yet show little change in their teaching practices".

What is the reason for such cautious attitude of the teaching community towards a potentially beneficial source of additional materials to use in education? Especially in this time of constantly developing digital modes of educational support, including a range of distant learning forms which reside in the digital environment, where does the link between teaching and a vast digital source of curated content brake?

Our paper explores this question. After a succinct description of the study methodology in 1.2, Section 2, provides a range of examples which build a multifaceted picture of the ideas digital library community has on their use for learning. Based on this overview, Section 3 provides a SWOT and gap analyses. The final Section 4 presents conclusions and ideas for further work.

\subsection{Methodology}

This study was conducted in June-September 2015. We performed systematic search for publications mentioning "digital libraries" and "learning" or "education" using two digital libraries : ACM Digital Library and IEEE Digital Library .We also used meta-search engines which allow to search both in published and grey literature (Google Scholar, ResearchGate, and Scopus ), as well as the repository for grey literature OpenGrey. Finally, we complemented where possible research publications with reports and strategic documents of institutions developing large digital libraries; deliverables of relevant EC-funded projects, and forecasts on the development of e-Learning. We excluded entries which were discovered in two or more sources. In addition, while we looked at historical developments we were particularly interested to collect evidence on trends from 2014-2015 in order to explore most recent developments and current solutions rather than older experiments.

Human content analysis was used to identify key themes in the ways digital libraries motivate and illustrate educational use; these findings are presented in Section 2. The major themes we chose include personas (where educational use is explicitly addressed); educational use cases; reference models of digital libraries. We also looked at the evidence which informs prioritising digitisation to cater for teaching needs and at the case where digital libraries are considered to be educational environments.

This analysis was further used to summarise the strengths, weaknesses, opportunities and threats, as well as for a gap analysis, which are presented in Section 3 of the paper. 


\section{Overview of the use of digital libraries in teaching}

In this section we are providing an overview of the major themes discovered in literature which illustrate the educational use of digital libraries. Since digital libraries is a term which is defined and interpreted in different ways, within this article we will adopt the definition of Deegan and Tanner [14] who summarise the following characteristics of a digital library:

1. "A digital library is a managed collection of digital objects.

2. The digital objects are created or collected according to the principles of collection development.

3. The digital objects are made available in a cohesive manner, supported by services necessary to allow users to retrieve and exploit the resources just as they would any other library materials.

4. The digital objects are treated as long-term stable resources and appropriate processes are applied to them to ensure their quality and survivability."

This definition emphasises on several aspects of digital libraries: Underlying collection development principles, cohesion, availability of services and longevity. These aspects are all guaranteeing to educational stakeholders. Having access to a collection of materials following spelled-out collection development principles, as well as underlying cohesiveness support relevance, set quality standards and a good range of the resources offered. The support for a service-oriented environment is vital for providing an environment meeting specific needs and expectations. Finally, the long term survivability is particularly relevant to education where the continuous access to specific resources would be a basic non-functional requirement.

In the following subsections we are summarizing various aspects of the educational use of digital libraries as developed by the digital library community.

\subsection{Personas with educational roles in digital libraries development efforts}

The method of personas is used in the domain of designing information systems to summarise evidence on information behaviour characteristics of the typical users. The evidence is used to put together a description of a set of typical characteristics of a user which is named and illustrated by a suitable image which helps the feeling of "personification". Such a description, called persona is then used by designers and is particularly helpful of internal testing of the product. The use of the persona method in the digital libraries is introduced in [15] and its usefulness is reiterated in [16]. The first set of personas developed for the purposes of Europeana [3] have been published in 2009 and included the teacher Maria, the school student Peter and the University student Julia among others (The remaining initial set of Europeana personas featured Jukka - ethnomusicologist; Sarah - shop assistant; William local history enthusiast, and Terese - University professor.) with a detailed initial description provided in [17] and refined further in 2011 [18]. Although the persona itself is well documented, its actual use in development is challenging to trace, hence it is also difficult to assess its usefulness. 
By 2013, Europeana moved to new types of personas where the teacher role had been abandoned - by that time the emphasis was on personas of a software developer, Albin; a PhD Student and blogger Loredana, and a Senior Project Coordinator from a University, Otto (Information exchanged in correspondence of the lead author with Dean Birkett from Europeana Office, November 2013). A further project around Europeana, EuropeanaCloud, used a set of 11 scenarios and 8 personas to illustrate use of digital cultural heritage over the cloud. This set of personas continued the trend in developing personas not related to teaching: all the uses are restricted to research tasks and the description of the new personas is quite shallow with personas being rather fictional, without integrating evidence of behaviour and information needs of real users [19]. Similarly to the initial set of Europeana personas featuring Maria, Peter, and Julia, subsequent use of the additional personas in the actual digital library development is not discussed in publications.

Besides Europeana, where the emphasis is on cultural content, the method of personas was applied also in different digital library environments. In 2010, Maness, Miaskewicz and Sumner [20] explored the needs of users of institutional repositories which can be considered a specific example of digital library representing academic output of the higher education institutions. They conducted a series of interviews with faculty and students and proposed four personas in total; two personas are based entirely on input of faculty members, one is based on student input, and one is mixed. Some initial work had also been made to apply personas method in capturing the key characteristics of learners. For example child-like personas which could help the development of a learning environment for mathematics were discussed in [21].

It is particularly interesting to note that the use of personas was extended as well to digital collections services developed by a major memory institution, the British Library. In 2013, when the Library was discussing the massive web redevelopment effort, the abundance of personas was seen as not only unmanageable, but also as potentially confusing for the web users: "The Library uses 15 'personas' to describe our audiences (Scientific, Technical, and Medical (STM) researcher, entrepreneur, start-up small company, Higher Education (HE) teacher, small business owner, social science post-graduate researcher, creative industries researcher, medium-sized business, librarian, Arts and Humanities $(\mathrm{A} \& \mathrm{H})$ post-doctoral researcher, $\mathrm{A} \& \mathrm{H}$ masters/PhD researcher, cultural visitor, learner undergraduate, undergraduate, government/Non For Profit (NFP)). This is unmanageable; it encourages niche developments and adds to the impression of multiple British Libraries on the web" [22]. It is worth noting however that even if the personas approach was not found to be feasible, the typical users specifically addressed in the tender documentation for the content management system of the library include higher education teacher and undergraduate learner [23]. The audience within the pilot includes the area of Learning bringing together Teacher and Pupils. "As a vertical audience, schools are key to driving access for future generations. The role of 'discovery' plays a significant role in the learning journey for this audience - a journey that would benefit from digital services that better 
aggregate and contextualise collection items. The National Curriculum provides a focus for curation of BL collections using multi-media. The authority and responsibility of the teacher also provides a controlled environment for piloting community functionality". This document also underlines that "The role and needs of the teacher as a key driver to effective use of the website", and "Content can be rolled-out to other audiences, such as Life-Long Learners and Graduates" [23, p. 7].

It is worth noting that generic models of digital libraries, such as [24] discuss actor roles - even if not on the same level of detail as the persona method requires. However, they do not consider specific areas of use, such as teaching or learning, but rather focus on the tasks a particular type of actor, e.g., digital library administrator, should perform. It would be worth exploring how teaching and learning roles could be integrated into the digital library reference model.

In conclusion, we could summarise that:

- The digital library community is interested in the educational applications and uses the method of personas to capture typical users with teaching or learning roles;

- There was an interest to personas from the educational domain in the initial years of developing Europeana [3], but those were gradually replaced by personas characterising new types of users;

- Although the method of personas requires evidence on information behaviour and technological competences, the personas developed so far do not capture in a systematic manner observations on the technological tools teachers/learners are using, besides such generic tools as preferred search engines and devices. This is a rather serious impediment in understanding the specific educational contexts. Besides the devices in use on the teachers' side it is essential to integrate observations on technological tools used to prepare and to deliver teaching material; similarly on the learner side, it is necessary to know what tools are used to access core and supplementary learning materials.

- The focus of memory institutions currently is on facilitating discovery of materials and improved aggregation and contextualisation of digital objects. While these are very helpful auxiliary functions, they are not a core to the learning environments where collating materials, as well as adding examples of identifiable level of difficulty and quality, are in greater demand.

\subsection{Teaching and learning scenarios and pilots}

A further insight into the way digital library professionals perceive the use of their resources in teaching and learning can be obtained from looking at scenarios for use and pilots being developed. The usefulness of development of scenarios for learning applications is illustrated in [25]. The educational use of digital libraries scenarios were preceded by the preparation of recommended sets of digital resources which could complement teaching in specific topics. One typical example from the Library of Congress, which brings together a set of links to recommended resources, is published in [26]. While these sets of suggestions are useful and save time to the teachers, the development of scenarios which illustrate real life 
situations and are used during the implementation stage for pilots' implementation is a powerful tool to integrate digital libraries in teaching and learning.

Within the context of Europeana, teaching scenarios are currently strongly branded as a case of re-use of digital material [27]. While from the point of view of a digital library this is a domain application, which might have not been anticipated when the digital library had been conceived, this interpretation has disadvantages from the point of view of the educational users. The term "re-use" applied in this context might be confusing because it is not widely used in the educational context. But even if one argues that this is a terminological issue which is a secondary matter, the overall take of Europeana currently is to produce separate subsets of materials accompanied with specialised tools which would be used in teaching. One such development is Historiana, which is described as follows: "The goal set out for the History Education theme application is to stimulate the reuse of cultural heritage resources for history education through easy-to-find and free-to-use educational resources (sources, learning activities and tools) that are designed to stimulate historical thinking, multiperspectivity and active learning" [27, p 19]. A further teaching domain is identified in natural history, where the main aim is to enhance the teaching providing serious games [ibid.]. This approach reinforces some of the observations made in the previous subsection: instead of finding ways to integrate digital libraries material into existing and well used learning environments, digital libraries act as an agent which offers novel tools for the educational domain. This might be a very successful approach if those tools are appreciated and gain popularity; for the time being it is too early to judge on the scale of their adoption. The elaboration on technical aspects of the History Pilot of Europeana [28] and the presentation of its capabilities [29] do not make a particularly strong connection to research on change of history teaching in the digital environment captured in the specialised literature, e.g. [30]; however such potential synergies could widen the outreach of the newly proposed tools to support historical research. There is also little connection to previous relevant efforts, e.g. the work done within the PATHS project which supports semantic enrichment and development of paths of exploration in large scale collections which demonstrated its development again on the case of Europeana objects and examples from the history domain [31].

Within the natural history domain, previous works deserving to be mentioned and linked to ongoing efforts can be found in [32] which elaborates on the use within e-Learning of resources from the Digital Library of Nature and Culture established by the National Museum of Natural Science in Taiwan, and [33] which summarises the experience of the project "Natural Europe" funded by the European Commission.

Further on-going research looked into non-functional requirements for educational uses of digital libraries - an area of research which is still quite rudimentary within the digital libraries' context [34]. When we discuss scenarios for use, it is worth mentioning that some institutions are building their solutions taking into account the evidence on the preference of the younger users to access web resources from mobile devices which has implications on the overall organisation of use of digital libraries. The British Library documentation on a 
tender of a content management system mentions that the "availability of reputable, accurate and syllabus relevant content, that is searchable and accessible through mobile channels, is increasingly important for both A-Level students and their teachers" [23, p.12].

In conclusion:

- There is a substantial showcasing work on teaching applications around specific domains of knowledge; most active within the cultural and scientific heritage context are the development in the domains of history and natural history.

- Some digital libraries chose to brand this work as 're-use' of digital objects, which might create confusion among teachers and learners, especially those who are not well versed in digital libraries terminology and encountered such applications for the first time.

- Bringing novel applications to the teaching domain, digital libraries might act as educational innovators. However they are still not integrating strongly channels to reach tools used within the current e-Learning environments.

\subsection{Teaching as a priority for digitisation}

A further aspect which is informative for digital libraries' development aimed at teaching provision is what additional materials need to be digitised, so that teaching needs are addressed at their best. Having in mind that the current level of digitisation is roughly estimated to capture some $10 \%$ of the available cultural and scientific heritage objects [27], the gaps in provision are definitely an aspect which needs to be addressed.

One study which looked at the user-driven digitisation needs within the UK higher education institutions, addressed the different uses of digitised material [35]. The impact of digitised materials on teaching was less popular among the study participants compared to the impact on research. The project followed a mixed method user study approach combining a questionnaire distributed among intermediaries from the higher education memory institutions (librarians, archivists, museum curators) and focus groups with end users (university teachers and students). Some of the comments recorded during the focus groups are thought provoking:

"Whilst the participants were in favour of introducing digitised collections to students, concerns were raised as to the level of technical literacy of students. Other issues concerned the importance of introducing students to the original source material and the need for time to integrate digitised collections into teaching programmes:

I'm staggered by the amount of undergraduates who tell me they don't know how to use the computer properly. They can't send attachments, they don't know how to type in URLs and things that I've told them to look at, they say they can't do it.

Digitisation would enable my students to interact with the material in ways other than they already do; it would increase access and place less pressure on the materials and resources themselves and on the library staff. Having said that, digitisation would not replace the consultation of the original materials. 
Students are not trained to use these materials.

Only the most motivated students will visit archives; digitisation would improve engagement." [35].

The aspects of research and teaching impact in the case of a special digital library with parliamentary documents which possible enhancements based on use were discussed in [36]; this study reiterates the stronger interest to the use of the collection for research.

An additional aspect of a strong teaching use is the competence of the digital library professionals to deliver teaching-related services. OCLC and RLUK in a recent survey on the Survey of Special Collections and Archives in the United Kingdom and Ireland [37] argued that "Users expect everything in libraries and archives to be digitised; national strategies for digitisation of rare and unique materials are therefore needed". This report also indicates need in further training related to teaching in special libraries where $18 \%$ of the respondents expressed such a need. It could be expected that stronger teaching competences, especially if they include a focus on eLearning, will help the library staff to cater better for the future needs of teachers and learners; this is one potential area for further work.

In conclusion, we could summarise that:

- When discussing digitisation priorities, teaching needs are behind research needs. In this sense, they are not a champion for further digitisation.

- There are a number of concerns on the skills to use digitised resources within the higher education environment. One can expect that some of the concerns raised would be even stronger in the secondary schools' setting.

- Library professionals feel the need for training in the domain of teaching. To be modern any further professional training programmes should also address the eLearning aspects.

- While teaching is explored as a potential digitisation need, self-learning needs to remain so far mostly obscure.

2.4. Digital libraries as educational environments. Some examples of Specialised tools

A further conceptualisation of the use of digital libraries within eLearning is the case when they are interpreted as learning environments. As early as in 2001, Le e [38] presented the following vision: "Digital library as a learning environments and resources network for science, mathematics, engineering, and technology education, that is:

- designed to meet the needs of learners, in both individual and collaborative settings;

- constructed to enable dynamic use of a broad array of materials for learning primarily in digital format; and

- managed actively to promote reliable anytime, anywhere access to quality collections and services, available both within and without the network".

As an aspiration this vision combines several essential components. The major question which still is not answered fourteen years after the publication is how exactly to meet the need of learners, how to enable dynamic use of materials and to 
guarantee reliability. We could assume that a part of the lack of specific guidance is due to the broad framework of learning contexts and tools. It would be helpful to provide illustrations of deployments which follow these recommendations within a specific learning context.

Further research emphasises on the positive influence on dynamic learning environments, interactivity and simulations on the learning outcomes: "As we give consideration to both how digital library learning experiences adapt to the needs of today's students, as well as help us generate more meaningful learning outcomes, we need to expand our repertoire and adopt more dynamic learning environments, such as simulation exercises in the online environment, rather than stick to the tried and true models such as the guided tutorial model commonly found today. Guided tutorials are fundamentally based on the prescriptive model and do not actively foster an interactive learning environment. Simulations, on the other hand, promote an interactive learning environment that provides students with a framework for constructing their own knowledge and models for future learning" [39, p. 202].

Once again, however, the connection to real-life implementations is not convincing. For example, discussing one of the digital libraries with the strongest use in teaching, NSDL, McIlvain argues: "Like many digital libraries, NSDL holds descriptive information (metadata) about the 130,000+ resources in its overall collection, and it provides a free and organised point of access to these resources and to its partner discipline- and audience-focused digital library portals (NSDL Pathways). Via this descriptive information NSDL points users to exemplary Webbased resources (lesson plans, activities, audio and video files, images, interactives), and the content NSDL refers to is owned and maintained by its providers and contributors. But access alone does not translate to effective teaching or learning, and NSDL is far more than a static repository of digital content" [40, p. 55].

An additional way of integrating digital libraries' content is the case when they are not considered as learning environments but as specialised tools that allow the use of their resources. Probably one of the most popular examples in this domain is the already mentioned IA (Instructional Architect) which had been developed to facilitate the use of NSDL resources. It "helps users, particularly teachers, discover, select, sequence, annotate, and reuse learning resources stored in digital libraries" $[13$, p. 1]. Although the general feedback about this tool is positive, its consistent and large-scale use by teachers remains more a wish than a reality.

Another development of a designated advertise in the days before this paper was nearly completed, was the multi-touch book on the history of the events leading to the First World War targeting secondary school citizens and anyone with historical interest. The multi-touch book was developed in a cooperation of Europeana, the European historical association EUROCLIO and a teacher with excellent record for innovation [41]. The development of the multi-touch book illustrated new partnerships. Since the book was launched in the days before submitting the article, data on its use are still not available. However how many teachers would be able to take part in such partnerships and develop their own materials? By all means providing high quality modern tools supporting educational activities is an asset for the educational community. But is this what this community 
needs most? How many teachers would like to use a resource prepared by someone else? How much flexibility this resource provides to be adapted to personal learning and teaching style? Does it take a small snapshot of the 45 million large Europeana, or communicate with larger available materials? Was the choice of Mac platforms the best one from the point of view of accessibility in the secondary school? Some of these questions surely will be debated in the next months.

In conclusion, we could summarise that:

- There is a noticeable trend to 'brand' digital libraries as educational environments. However, the evidence so far does not support that they are fit for this purpose.

- Specialised tools developed either to facilitate educational uses or to serve as a mini learning environment (covering one specific topic) exist. However, in the first case the uptake by teachers is not meeting the expectations. The latter case is relatively novel and there are no sufficient observations on the success of the approach.

\section{SWOT and gap analyses}

The main trends presented in Section 2 identified a number of attempts on the side of digital libraries development to bridge the gap and find practical ways to showcase the usefulness of digital libraries in educational context.

Recently, Europeana published a report on the use of the digital library in education and learning [42] which advocates the following set of four key recommendations:

- "Set up a Europe-wide structured dialogue between policy-makers, cultural heritage institutions and educators to improve access and reduce duplication of effort.

- Prioritise the provision of 'Fit for Education and Learning' content by cultural heritage institutions and ministries.

- Emphasise the development of inclusive and accessible digital learning resources.

- Promote open licences and improve the access and re-use conditions that underpin education and learning".

These recommendations were developed with the input of experts from 21 countries and while generally useful, there is insufficient elaboration on the actions which would succeed in bringing together the various stakeholders mentioned directly in the recommendations or active in the respective areas. The aims for openness, inclusiveness, and provision of content explicitly marked as "Fit for Education and Learning" are ahead of the current necessities since they would help to boost the volume of content open for educational use. However, the paradox is that the first condition for use is not availability and accessibility but meeting the demands of the users which are not present in the recommendations. In this particular case the users are either the educators (teachers), or the end users (learners). As discussed in Section 2, the current knowledge about the needs, 
demands and expectations within the eLearning context is limited and thus delays the uptake of developed digital library services aimed at training and learning.

In order to gain a deeper insight into the situation we provide below a Strengths, Weaknesses, Opportunities and Threats (SWOT) analysis summarizing the emerging themes from the literature review presented in Section 2. The weaknesses and threats in the SWOT analysis are actually the areas which, if tackled, can lead to a positive change in the domain of educational use of digital libraries.

Table 1. SWOT analysis on the application of DLs in e-Learning (please note that the rows in the neighbouring columns of the table are not logically connected to each other)

\begin{tabular}{|c|c|c|}
\hline & Positive & Negative \\
\hline & Strengths & Weaknesses \\
\hline \multirow[t]{2}{*}{ 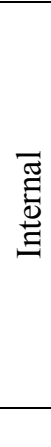 } & $\begin{array}{l}\text { - Educational use is widely } \\
\text { perceived as a positive trend by } \\
\text { the digital libraries community. } \\
\text { - Developers of digital libraries } \\
\text { already have experience with } \\
\text { personas, scenarios, as well as } \\
\text { tools aimed to be used for } \\
\text { teaching and learning }\end{array}$ & $\begin{array}{l}\text { - Needs of the educational community for additional } \\
\text { digital content provisions have not been analyzed in } \\
\text { detail and understood by the digital library community. } \\
\text { - Branding of educational applications of digital } \\
\text { libraries as 're-use' might be confusing for educators } \\
\text { who are not familiar with digital libraries' concepts. } \\
\text { - Most personas and scenarios are fictional and not } \\
\text { sufficiently grounded in real life practice. } \\
\text { - There are more pilot activities supporting teaching; } \\
\text { learning (and in particular personal learning) remains } \\
\text { marginalized for the time being }\end{array}$ \\
\hline & Opportunities & Threats \\
\hline 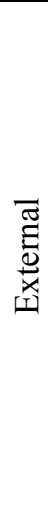 & $\begin{array}{l}\text { - Information needs of teachers } \\
\text { and learners are currently in the } \\
\text { focus of research in the wider } \\
\text { domain of information behaviour } \\
\text { studies; this knowledge can help } \\
\text { in development of personas, } \\
\text { scenarios and tools. For the time } \\
\text { being there is limited use of it. } \\
\text { - The library community } \\
\text { acknowledges the need in further } \\
\text { training regarding teaching but } \\
\text { systematic programmes } \\
\text { addressing eLearning are not } \\
\text { currently available }\end{array}$ & $\begin{array}{l}\text { - The introduction of "Fit for Education and Learning" } \\
\text { content by cultural heritage institutions and ministries } \\
\text { will bring more attention to the educational uses, but it } \\
\text { will not resolve the use itself if the educational } \\
\text { community does not have the tools for easy access. } \\
\text { - Novel domains like information visualisation } \\
\text { (including its use in mobile applications), big data, 3D } \\
\text { modelling and printing are still not systematically } \\
\text { integrated in the educational use of digital libraries } \\
\text { although relevant. This creates a threat of a divide } \\
\text { between modern areas influencing learning, younger } \\
\text { learners' expectations, and the traditional digital library } \\
\text { practice }\end{array}$ \\
\hline
\end{tabular}

Our subsequent step was to perform a gap analysis. If the current state can be summarised as "While digital libraries' developers are eager to support e-Learning (in particular) or teaching and learning (in general), currently there is a mismatch of their supply and educational demand", the desired state is "There are convenient tools which allow the use of digital library materials in education, feeding materials into e-Learning environments with evidence of growing use". One could argue that the emphasis still should be on the content, but already having tens of millions of digital objects, as demonstrated in Section 1 of the paper, in fact means that the issue is not to provide more content or even to mark which is fit for educational purposes since any material could be potentially useful at some educational level. The issues currently faced are more along the lines of selecting the most appropriate 
content and providing an interface between the digital libraries and the eLearning environments. We tackled three most essential gaps emerging from the previous analysis of literature: the general awareness on digital libraries and their potential educational uses; the role of teachers and the support for learners. Investing in these three areas should help to connect a better coordinated link between digital libraries and e-Learning.

Table 2. Gap analysis

\begin{tabular}{|c|c|c|}
\hline $\begin{array}{c}\text { What is not } \\
\text { met? }\end{array}$ & Current situation & Possible solutions \\
\hline $\begin{array}{l}\text { Domain } 1 . \\
\text { Digital } \\
\text { libraries "not } \\
\text { on the radar" } \\
\text { of e-Learning }\end{array}$ & $\begin{array}{l}\text { A recent bibliometric study of } \\
\text { the trends in e-Learning which } \\
\text { explored the evolution learning } \\
\text { in the digital environment from } \\
1960 \text { to } 2014 \text { identified } 22 \\
\text { concepts related to it (e.g., } \\
\text { "computer-assisted instruction", } \\
\text { or "distributed open } \\
\text { collaborative courses"); however } \\
\text { neither digital libraries or } \\
\text { educational digital libraries are } \\
\text { among them [43] }\end{array}$ & $\begin{array}{l}\text { Better relationships are needed with the } \\
\text { current movers in the domain of eLearning- } \\
\text { not only the users (teachers and learners) but } \\
\text { the governmental bodies which implement } \\
\text { national policies and strategic projects like } \\
\text { the ones for introducing tablets in schools, } \\
\text { as well as the industrial players developing } \\
\text { new educational applications and } \\
\text { environments }\end{array}$ \\
\hline $\begin{array}{l}\text { Domain } 2 \text {. } \\
\text { The pattern of } \\
\text { using digital } \\
\text { library } \\
\text { materials by } \\
\text { teachers } \\
\text { needs to shift } \\
\text { from "flirting" } \\
\text { to persistent } \\
\text { use }\end{array}$ & $\begin{array}{l}\text { If the teachers are seen as } \\
\text { champions of use of digital } \\
\text { libraries' content in teaching, } \\
\text { their engagement should go } \\
\text { beyond the typical "trial" style. } \\
\text { For example the study on the } \\
\text { teacher engagement with NSDL } \\
\text { described the current state based } \\
\text { on the observation of the } \\
\text { engagement of } 150 \text { teachers [13] } \\
\text { and found that the overall } \\
\text { enthusiasm of teachers during a } \\
\text { training session on integrating } \\
\text { digital libraries in teaching is not } \\
\text { consistent with the subsequent } \\
\text { low uptake }\end{array}$ & $\begin{array}{l}\text { Arriving to a better understanding of the } \\
\text { teachers' context of use is an essential } \\
\text { prerequisite to offer solutions which will } \\
\text { facilitate this type of users. Currently the } \\
\text { prevailing attitude is "This is good, so } \\
\text { what?" A general trend explored in the } \\
\text { impact of digital resources is that they are } \\
\text { very competitive to attract users/visitors and } \\
\text { this is also true for the teachers' community } \\
\text { which needs more than just interesting } \\
\text { illustrations. The offering should integrate in } \\
\text { the routine tasks of the teachers preparing } \\
\text { and delivering their classes. For example, if } \\
\text { the preferred technology they use is } \\
\text { PowerPoint, do they have plug ins which } \\
\text { allow easy search and copying of digital } \\
\text { content into their presentations? }\end{array}$ \\
\hline $\begin{array}{l}\text { Domain } 3 \\
\text { Tools } \\
\text { generating } \\
\text { pedagogical } \\
\text { sequences/gui } \\
\text { dance aiding } \\
\text { the learners } \\
\text { are still not } \\
\text { widely } \\
\text { available and } \\
\text { adopted }\end{array}$ & $\begin{array}{l}\text { There is still a need to provide } \\
\text { tools which help individual } \\
\text { learners and enhance their access } \\
\text { to content relevant to their } \\
\text { learning experiences: "A key } \\
\text { challenge facing educational } \\
\text { technology researchers is how to } \\
\text { provide structure and guidance } \\
\text { when learners use unstructured } \\
\text { and open tools such as digital } \\
\text { libraries" [44, p. 67] }\end{array}$ & $\begin{array}{l}\text { This domain also requires better } \\
\text { understanding of users, but of a different } \\
\text { kind. Mostly related to unsupervised or } \\
\text { loosely supervised learning, with a focus on } \\
\text { the end users - learners who are searching } \\
\text { for additional materials to enhance their } \\
\text { knowledge }\end{array}$ \\
\hline
\end{tabular}




\section{Discussion and conclusions}

This paper presented an overview of the current approaches to close the chasm between the potential usefulness of digital libraries in education and the eLearning environments currently in use. The growth of digitised collections is allowing unprecedented access to digital content. For example, the Enumerate project which collects quantitative data on the European digitisation found in its most recent survey that $90 \%$ of the respondents are memory institutions with collections to be kept for future generations and $84 \%$ of institutions have a digital collection [45]. But how these could find their way to eLearning?

With this digital material residing in various digital libraries, the users who could potentially benefit from the educational use first have the challenge to discover where the material most suitable to their needs resides. Current initiatives which help to aggregate digital content help to some extent: "As with our partners, educators were excited about the unique, "one-stop shopping" nature of DPLA that allows them to find an abundance of great material without visiting many different sites" [46].

However, is it sufficient for users coming from the educational domain to find an abundance of material? How this material can seamlessly fit into their contexts of use?

The complexity of the use of digital libraries content within education is due to the fact that we cannot speak of educational uses without further qualifying what sort of educational environments we are having in mind. There are multiple recent developments - some to support supervised classroom teaching, others to facilitate individual learning. Systematic analysis of their potentially different needs in digital content have not been studies in detail, to mention just the most popular ones: Learning management systems, Massive Online Open Courses (MOOCs), Web based courses; Adaptive intelligent educational systems; Personal learning environments; Educational open data; Social media.

Instead of looking for 1:1 relationship, one has to see the multiple relationships within. On the highest level of use of technology in education, a recent report of OECD showed alarming evidence that technology does not necessarily improve learning but, on the contrary, can be a major distractor: "The impact of technology on education delivery remains sub-optimal, because we may overestimate the digital skills of both teachers and students, because of naïve policy design and implementation strategies, because of a poor understanding of pedagogy, or because of the generally poor quality of educational software and courseware" [47, p. 4]. Since the use of digital library content is only a small part of the larger processes of applying technology in education, it inevitably will be influenced by all issues mentioned above.

Specific forms of digital material also are influenced by technological developments: "Due to the increased price of textbook, schools are quickly adopting different solutions. This means not only creating e-Books (both paid-for and downloaded), but also providing easy access to e-Books (renting without ownership). However, the anticipated boom of e-Book sales didn't happen in the 
past year. The newest trend is the scouting for an environment that can host e-Books, as a sort of Learning Management System with a library of books" [7, p. 35].

To make this even more complicated, when one moves from the technological domain to the memory institutions which provide the content and are currently expected to contextualise it for educational use, there are substantial concerns on their skillsets: "Only recently it was still difficult to convince library administrators of the importance of instructional design as a part of the regular activities that a library engages in... This reflects the very justified concern on the part of administrators for the need for a broad range of skills necessary for libraries in order to be effective service organisations, along with the necessity for libraries to fund many modes of instruction" [48, p. 9].

In general, this complex environment leads to the outcome that digital libraries are not popular as a trustworthy source of materials for e-Learning. For example, a study combining an online survey of 2,500 faculty members and 11 focus groups of 50 participants from the USA found that "Science, Technology, Engineering, Mathematics (STEM) instructors... do not differentiate between digital libraries and other kinds of content that comes from the web, they seek content to supplement traditional teaching methods and their reliance on Google and personal networks impedes their ability to recall the primary sources of useful content" [49] something which is coherent with our earlier observation that the branding of the use of digital libraries' content for education needs an improvement.

These observations illustrate the complexities of the environment and the tasks. Based on our analysis, we are summarising in Fig. 1 the areas which need to be tackled with the highest urgency and importance. While the current emphasis in demonstrating the usefulness of digital libraries for teaching and learning is on developing tools (also followed by Europeana), we believe this trend of work is less urgent and important compared to improving the understanding of the information needs and digital environments of learners.

Research on information needs related to the styles of engagement with digital content has a number of highlights in the CIBER study on the 'google generation' [50], followed by a research on the engagement of young people with audio-visual materials [51], or specific digital libraries, such as NSDL [52] and Europeana [53] within the larger picture of changes in the way humans learn: "Learning cohorts from previous generations who were accustomed to a limited range of educational resources acclimated to learning through primarily aural and read/write modalities. The educational environment for millennial generation learners has been dominated by technology. As a result a variety of learning styles, not apparent in previous generations, have become common. These learning styles are incidental to novel resources to which learners now have access. Strategies designed to promote successful knowledge acquisition for learners of any style should incorporate a variety of the ever-increasing array of available innovative educational paradigms and digital resources" [54].

We also need to differentiate between the needs and styles of learners on different levels. The recent background study related to use of DPLA materials in 
learning found that "Perhaps not surprisingly, instructors in K-12 (a term for primary and secondary education used in countries like USA, Canada, Turkey among others) and higher education follow fairly different patterns when they search for online education resources. This search was highly idiosyncratic for participants in the higher education focus group, whereas K-12 participants were generally familiar with a core group of resource sites... In addition, higher education participants were more interested in finding raw materials by themselves than finding materials that came with preset ideas for instructional use" [46].

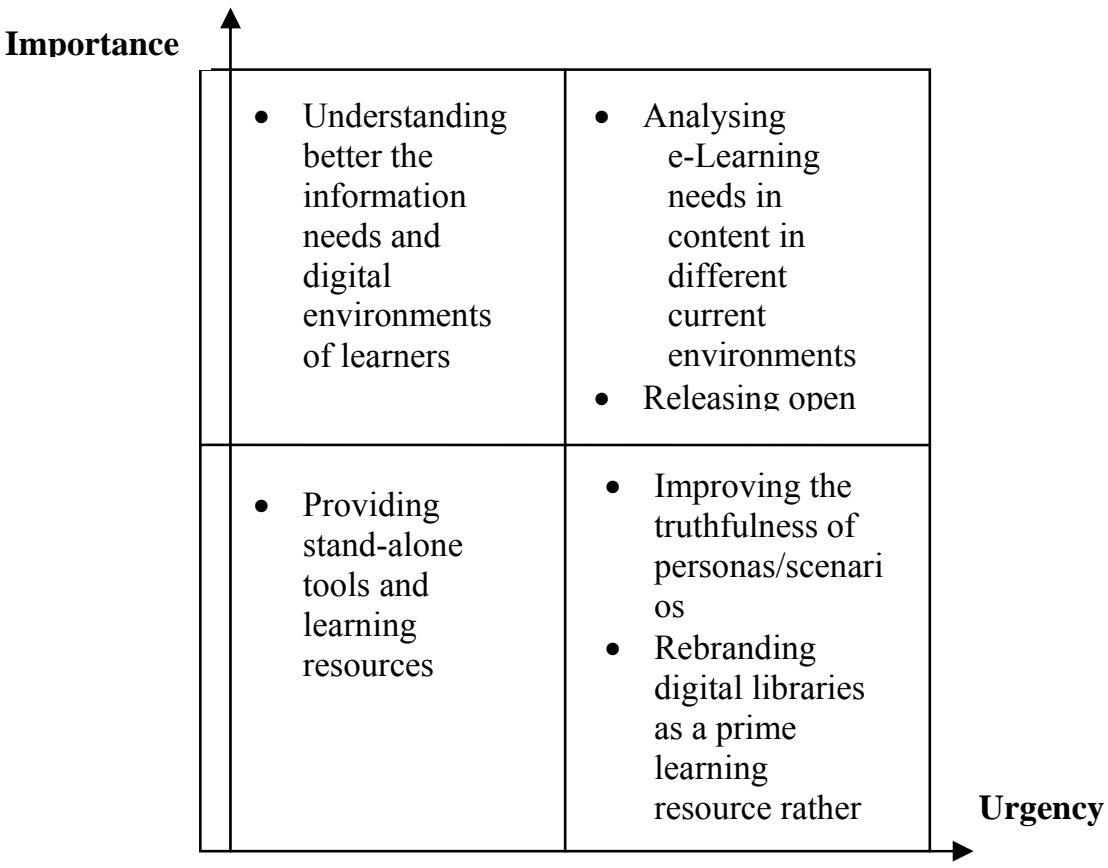

Fig. 1. Matrix of priorities

In practical terms we believe that the areas of highest importance and urgency are to achieve a clear understanding of needs in content in eLearning, and to release more open educational resources $[55,56]$. The better understanding of needs - not as perceived by the digital library community but as experienced in the educational community, will help to bridge the gap between both communities. In addition, offering more open educational resources would be a helpful strategic step for strengthening the engagement of digital libraries with education.

We hope that the systematic efforts in these directions will bring a positive change and the wealth of digital libraries' resources and will be of better service in education for the benefit of all teachers and learners.

Acknowledgment: The research work presented in this paper is partially supported by the FP7 Grant 316087 AComIn "Advanced Computing for Innovation", funded by the European Commission in the FP7 Capacity Programme in 2012-2016. The results were presented at the Workshop "Big Data in Education and Digital Collections" held on 29 June 2015 at the Institute of Information and Communication Technologies, Bulgarian Academy of Sciences. The authors also would like to express their gratitude to Prof. Darina Dicheva and Prof. Christo Dichev for the helpful and insightful discussions. 


\section{References}

1. S m i th, A. Why Digitize? CLIR, Washington DC, 1999. 13 p. http://www.clir.org/pubs/reports/pub80-smith

2. World Digital Library (website). http://www.wdl.org/en/

3. Europeana (website). http://www.europeana.eu/portal/

4. DPLA - Digital Public Library of America (website). http://dp.la

5. Google Books (website). https://books.google.com/

6. W is chenbart, R., C. Carrenho, J. Celaya, V. Licher, M. Kovac, V. Mallya. Global eBook: A Report on Market Trends and Developments, 2014. 157 p. http://www.wischenbart.com/upload/1234000000358_04042014_final.pdf

7. e-Learning Market Trends \& Forecast 2014-2016 Report. Docebo, 2014. 47 p. https://www.docebo.com/landing/contactform/elearning-market-trends-and-forecast2014-2016-docebo-report.pdf

8. A Strategy for the Digital Content Industry in Ireland, Forfás, Dublin, 2002. 23 p. http://www.skillsireland.ie/media/forfas021101c_digital_content_strategy.pdf

9. Pumilia-Gnarini, P. M., P. Favaron, E. Pacetti, E. B is hop, J. L. Guerra. Handbook of Research on Didactic Strategies and Technologies for Education: Incorporating Advancements. Vol. 1-2. USA, IGI Global, 2013. 829 p.

10. B r e e d in g, M. Maximizing the Impact of Digital Collections. - Computers in Libraries, Vol. 29, 2009, No 4, pp. 32-34.

11. T a n n e r, S., M. D e e g a $n$. Inspiring Research, Inspiring Scholarship. The Value and Benefits of Digitised Resources for Learning, Teaching, Research and Enjoyment. London, JISC, 2011. $54 \mathrm{p}$. http://www.kdcs.kcl.ac.uk/fileadmin/documents/Inspiring_Research_Inspiring_Scholar ship_2011_SimonTanner.pdf

12. B org m a n, C., G. L e a z e r, A. Gilli l a n d-S w e t l a nd, K. Millw o o d, L. Ch a m p e ny, J. Finley, L. Smart. How Geography Professors Select Materials for Classroom Lectures: Implications for the Design of Digital Libraries. - In: H. Chen, M. Christel, E. Lim, Eds., JCDL'04: Proc. of 4th ACM/IEEE-CS Joint Conference on Digital Libraries (Tucson, AZ, 7-11 June 2004). New York, Association for Computing Machinery, 2004, pp. 179-185.

13. Re cker, M., J. Dorward, D. Daw s on, S. Hali or is, Y. Li u, X. M a o, B. Palmer, J. P a rk. You Can Lead a Horse to Water. - In: Proc. of Joint Conference on Digital Libraries, ACM, New York, 2005, pp. 1-7.

14. D e e g a n, M., S. T a n n e r. Digital Futures: Strategies for the Information Age. London, Library Association Publishing, 2002.

15. R a s m u s s e n G. K., G. P e t e r s e n. Personas. - In: M. Dobreva, O’Dwyer, A. P. Feliciati, Eds. User Studies in Digital Library Development. London, Facet Publishing, 2012, pp. 105-114.

16. Fox, R. Dramatis Personae. - OCLC Systems \& Services: International Digital Library Perspectives, Vol. 30, 2014, No 2, pp. 69-73.

17. Milestone M3.2.3 Personas Catalogue. EuropeanaConnect, 2009. http://www.europeanaconnect.eu/documents/M3.2.3_eConnect_PersonasCatalogue_v1. 0_20091228.pdf

18. Milestone M3.2.3 Personas Catalogue Update. EuropeanaConnect, 2011. http://www.europeanaconnect.eu/documents/M3.2.3_eConnect_PersonasCatalogue_up date.pdf

19. Duval, E., G. Parra, H. Van Der Berg, A. Jentszch, D. Dietrich, N. Mon a o us elis, G. Sto its is. Deliverable 3.1.Personas, Scenarios and Use Cases. EuropeanaCloud, 2013.

http://pro.europeana.eu/files/Europeana_Professional/Projects/Project_list/Europeana_ Cloud/Deliverables/D3.1\%20Personas,\%20scenarios\%20and\%20use\%20cases.pdf 
20. M an ess, J., T. Mi a ski ew i cz, T. S u mner. Using Personas to Understand the Needs and Goals of Institutional Repository Users. - D-Lib Magazine, Vol. 14, 2010, No 9/10. http://dlib.org/dlib/september08/maness/09maness.html

21. V a r e la, S., C. Ha 11, H. B a n g. Creating Middle School Child-Based Personas for a Digital Math Practice Application. - In: S. Carliner, C. Fulford, N. Ostashewski, Eds., Proc. of EdMedia: World Conference on Educational Media and Technology, Association for the Advancement of Computing in Education (AACE), Montral, Quebec, 2015, pp. 694-699.

22. British Library Web Redevelopment: Update Report. London, British Library, 2013. 22 p. http://www.bl.uk/aboutus/foi/pubsch/pubscheme4/BLB1386.pdf

23. Instructions to Tenderers. Content Management System. London, British Library, 2013. http://www.bl.uk/aboutus/foi/transparency/contracts/Contract\%20SMC8301.pdf

24. Candela, L., D. Castelli, N. Ferro, G. Koutrika, C. Meghini, P. Pagano, S. Ros s, D. Soerge 1, M. Ag os ti, M. Dobreva, V. Kat i fori, H. S chuldt. The DELOS Digital Library Reference Model. Foundations for Digital Libraries. ISTI-CNR, Pisa, 2008. $215 \mathrm{p}$.

25. T a y 1 o r, J., D. E v a n s. Pulling Together: Keeping Track of Pedagogy, Design and Evaluation through the Development of Scenarios - A Case Study. - Learning, Media and Technology, Vol. 30, 2005, No 2, pp. 131-145.

26. Teacher's Guide. Primary Source Set: Maps from the World Digital Library (web resource). http://www.loc.gov/teachers/classroommaterials/primarysourcesets/wdl/pdf/teacher_gui de.pdf

27. Transforming the World with Culture: Next Steps on Increasing the use of Digital Cultural Heritage in Research, Education, Tourism and the Creative Industries. Europeana Foundation, The Hague, 2015. 31 p.

http://pro.europeana.eu/files/Europeana_Professional/Publications/Europeana\%20Pres idencies\%20White\%20Paper.pdf

28. Documentation of History Pilot. Europeana, The Hague, 2014. 7 p. http://labs.europeana.eu/files/labs/apps/technical-description-of-the-history-educationpilot-introduction.pdf

29. D3.2 - Documentation of Business Model Propositions. Europeana Creative, 2014. 48 p. http://pro.europeana.eu/files/Europeana_Professional/Projects/Project_list/Europeana_ Creative/Deliverables/eCreative_D3.2_KL_1.0.pdf

30. Mills Ke 11 y, T. Teaching History in the Digital Age. The University of Michigan Press, 2013. $184 \mathrm{p}$.

31. Agirre, E., O. Lopez de Lacalle, P. Clough, M. S teven son. PATHS: Personalised Access To Cultural Heritage Spaces. - In: IV Jornadas TIMM Tratamiento de la Información Multilingüe y Multimodal 7 y 8 de Abril de 2011: 69, 2011.

http://timm.ujaen.es/wp-content/uploads/2014/03/timm2011_submission_9.pdf

32. Che n, C.-M., S. Lin. Assessing Effects of Information Architecture of Digital Libraries on Supporting e-Learning: A Case Study on the Digital Library of Nature \& Culture. Computers \& Education, Vol. 75, 2014, pp. 92-102.

33. S c h midt, K., H.-C. S ch mitz, M. W o l pers. Developing a Network of Cultural Heritage Objects Repositories for Educational Purposes. Metadata and Semantic Research. Springer, Berlin Heidelberg, 2011, pp. 337-348.

34. Avellis, G. Non Functional Requirements Assessment and Traceability in Multimedia Educational Software. - In: Proc. of 2013 International Conference on Education and Educational Technologies, 2012, pp. 215-221.

35. B irre 11, D., M. D obreva, G. Dunsire, J. Griffiths, R. Hartley, K. Menzies. The DiSCmap Project: Digitisation of Special Collections: Mapping, Assessment, Prioritisation. New Library World, Vol. 112, 2011, No 1/2, pp. 19-44.

36. H u g h e s, L., P. E 11, M. D o b r e v a, G. K n i g h t. Assessing and Measuring Impact of a Digital Collection in the Humanities. - LLC: The Journal of Digital Scholarship in the Humanities, 2013.

37. Dooley, J. M., R. B eckett, A. Cullingford, K. Sambrook, C. Shepard, S. W o rra 11. Survey of Special Collections and Archives in the United Kingdom and Ireland, Dublin, Ohio: OCLC Research. 2013. 259 p. 
http://www.oclc.org/resources/research/publications/library/2013/2013-01.pdf.

38. L e e, L. Z. Growing a National Learning Environment and Resources Network for Science, Mathematics, Engineering, and Technology Education: Current Issues and Opportunities for the NSDL Program. - D-Lib Magazine, Vol. 7, 2001, No 3, pp. 65-73.

39. Ce rvo ne, F. Learning, Adaptation, and Digital Libraries. - OCLC Systems \& Services: International Digital Library Perspectives, Vol. 29, 2013, No 4, pp. 200-203.

40. McIlvain, E. NSDL as a Teacher Empower Point: Expanding Capacity for Classroom Integration of Digital Resources. - Knowledge Quest, Vol. 39, 2010, No 2, pp. 54-63.

41. Greenhalgh, I. Download Our New iTunes U Course and Multi-Touch Book on the First World War! (blog post). 13 October 2015.

http://blog.europeana.eu/2015/10/download-our-new-itunes-u-course-and-multi-touchbook-on-the-first-world-war/

42. Europeana for Education and Learning. Policy Recommendations. Europeana, 2015. 8 p. http://pro.europeana.eu/files/Europeana_Professional/Publications/Europeana\%20for \%20Education\%20and\%20Learning\%20Policy\%20Recommendations.pdf

43. A p a r i c i o, M., F. B a c a o, T. O live ir a. Trends in the e-Learning Ecosystem: A Bibliometric Study. - In: Proc. of AMCIS'2014, 2014. 11 p. http://aisel.aisnet.org/amcis2014/Posters/ISEducation/7

44. Ok oye, I., T. S u mne r, S. B ethard. Automatic Extraction of Core Learning Goals and Generation of Pedagogical Sequences through a Collection of Digital Library Resources. In: Proc. of 13th ACM/IEEE-CS Joint Conference on Digital Libraries, ACM, New York, 2013, pp. 67-76,

45. Overview of the Results from the Enumerate Core Surveys. Enumerate Project, 2015. http://pro.europeana.eu/enumerate/statistics/results

46. A b b ott, F., D. Cohen. Using Large Digital Collections in Education: Meeting the Needs of Teachers and Students. Digital Public Library of America, 2015. 28 p. http://dp.la/info/wp-content/uploads/2015/04/Using-Large-Collections-in-EducationDPLA-paper-4-9-15-2.pdf

47. Students, Computers and Learning. Making the Connection. OECD, Paris, 2015. 200 p.

48. Fox, R. Proactive Pedagogy. - OCLC Systems \& Services: International Digital Library Perspectives, Vol. 29, 2013, No 1, pp. 7-12.

49. M c M artin, F., E. Ivers on, C. M a n d u ca, A. Wolf, G. Morgan. Factors Motivating Use of Digital Libraries. - In: JCDL06: Proc. of 6th ACM/IEEE-CS Joint Conference on Digital Libraries, New York, 2006, pp. 254-255.

50. CIBER The Information Behaviour of the Researcher of the Future. British Library, 2008.

51. Nicholas, D., I. Rowlands, D. Clark, P. Willi a m s. Google Generation II: Web Behaviour Experiments with the BBC. - Aslib Proceedings: New Information Perspectives, Vol. 63, 2011, No 1, pp. 28-45.

52. Z a v a 1 i n a, O., E. V a s s i 1 i e va. Understanding the Information Needs of Large-Scale Digital Library Users. - Library Resources \& Technical Services, Vol. 58, 2014, No 2, pp. 84-99.

53. D o breva, M., E. M c Culloch, D. B irre 11, Y. Ün a 1, P. Fe li c i a ti. Digital Natives and Specialised Digital Libraries: A Study of Europeana Users. - In: S. Kurbanoğlu et al., Eds. IMCW'2010, Springer, Heidelberg, 2010, pp. 45-60.

54. D i L u 11 o, C. Learners of a New Generation. - In: L. Chan, W. Pawlina, Eds. Teaching Anatomy. Berlin Heifelberg, Springer, 2015, pp. 11-21.

55. D i c h e v, C., D. D i c h e va, G. A g r e, G. A n g e lova. Trends and Opportunities in Computer Science OER Development. - Cybernetics and Information Technologies, Vol. 15, 2015, No 3, pp. 114-126.

56. Dichev, C., D. Dicheva, G. Agre, G. Angelova. Current Practices, Trends and Challenges in K-12 Online Learning. - Cybernetics and Information Technologies, Vol. 13, 2013, No 3, pp. 91-110. 